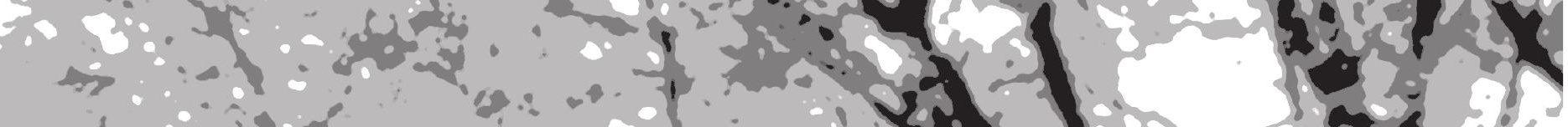

at

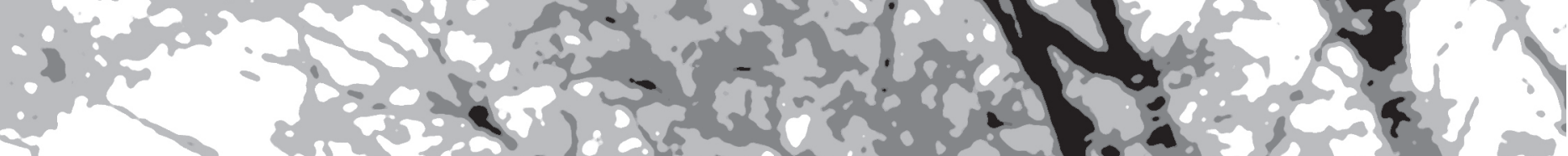

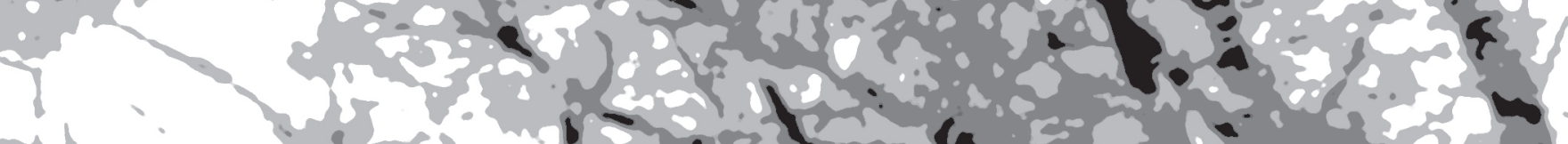

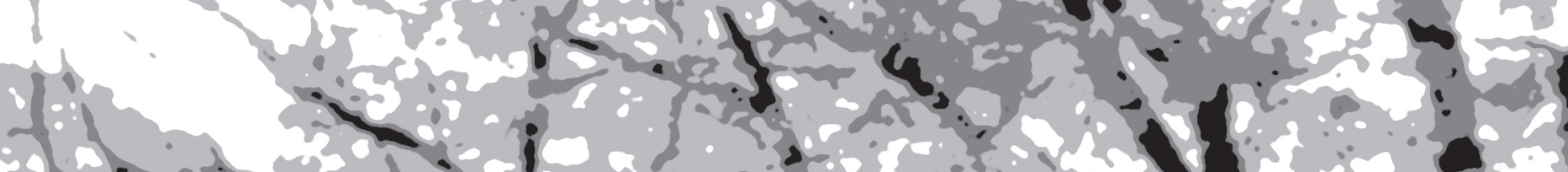

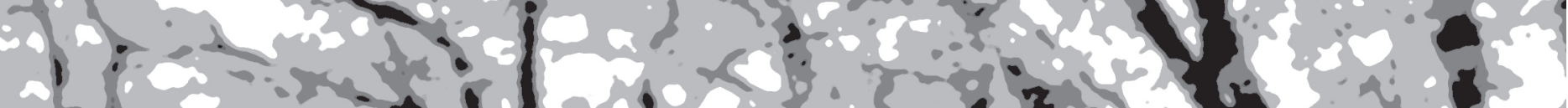
$1 e^{2}+1 y^{2}$ $-10-1=1$

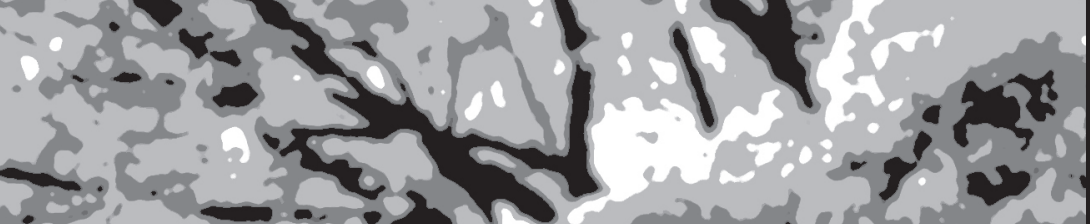

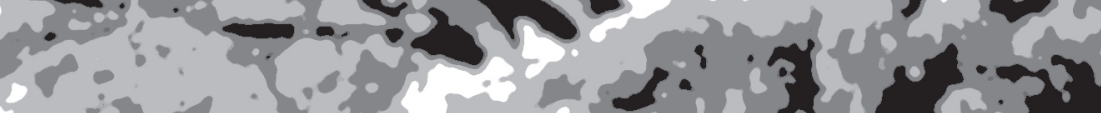

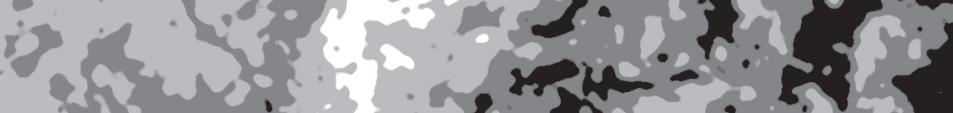
of w 1 of anth

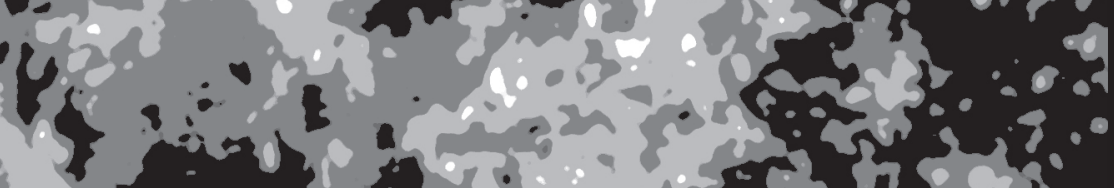

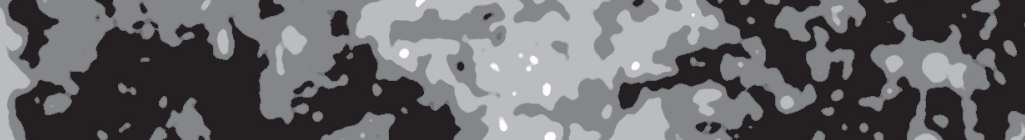

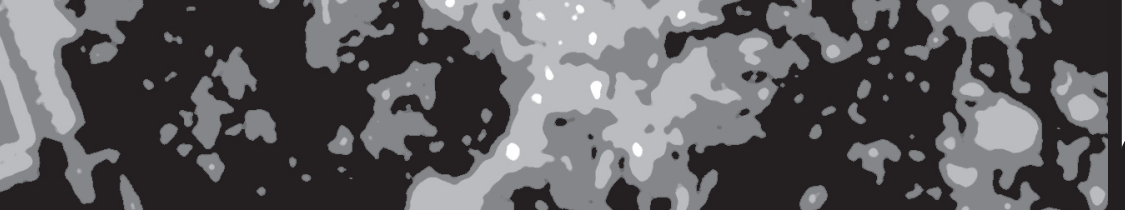

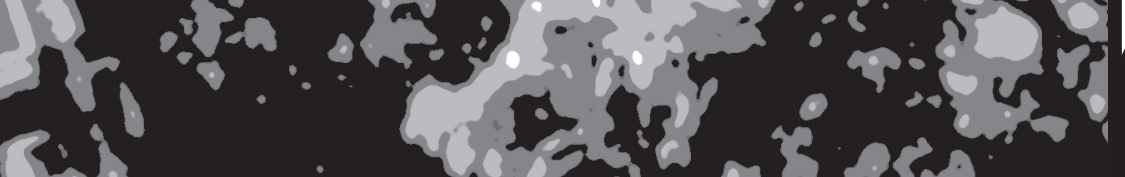
40

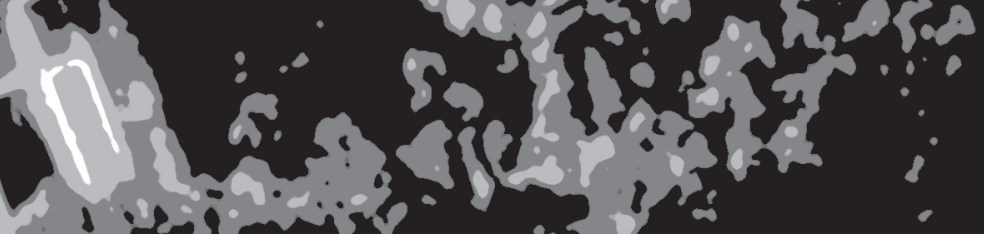

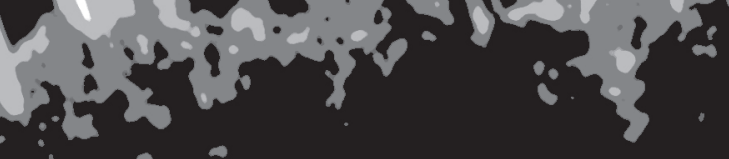

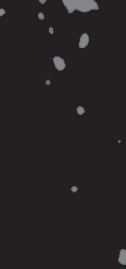

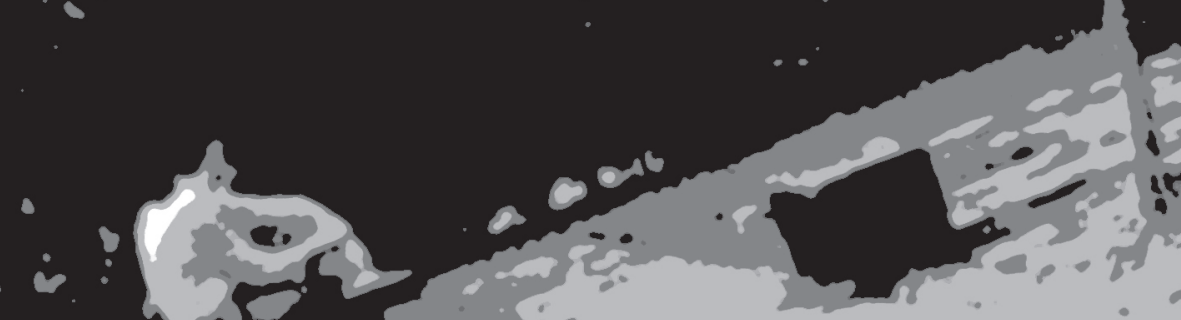




\section{A universidade brasileira,}

\section{AFRÂNIO MENDES CATANI}
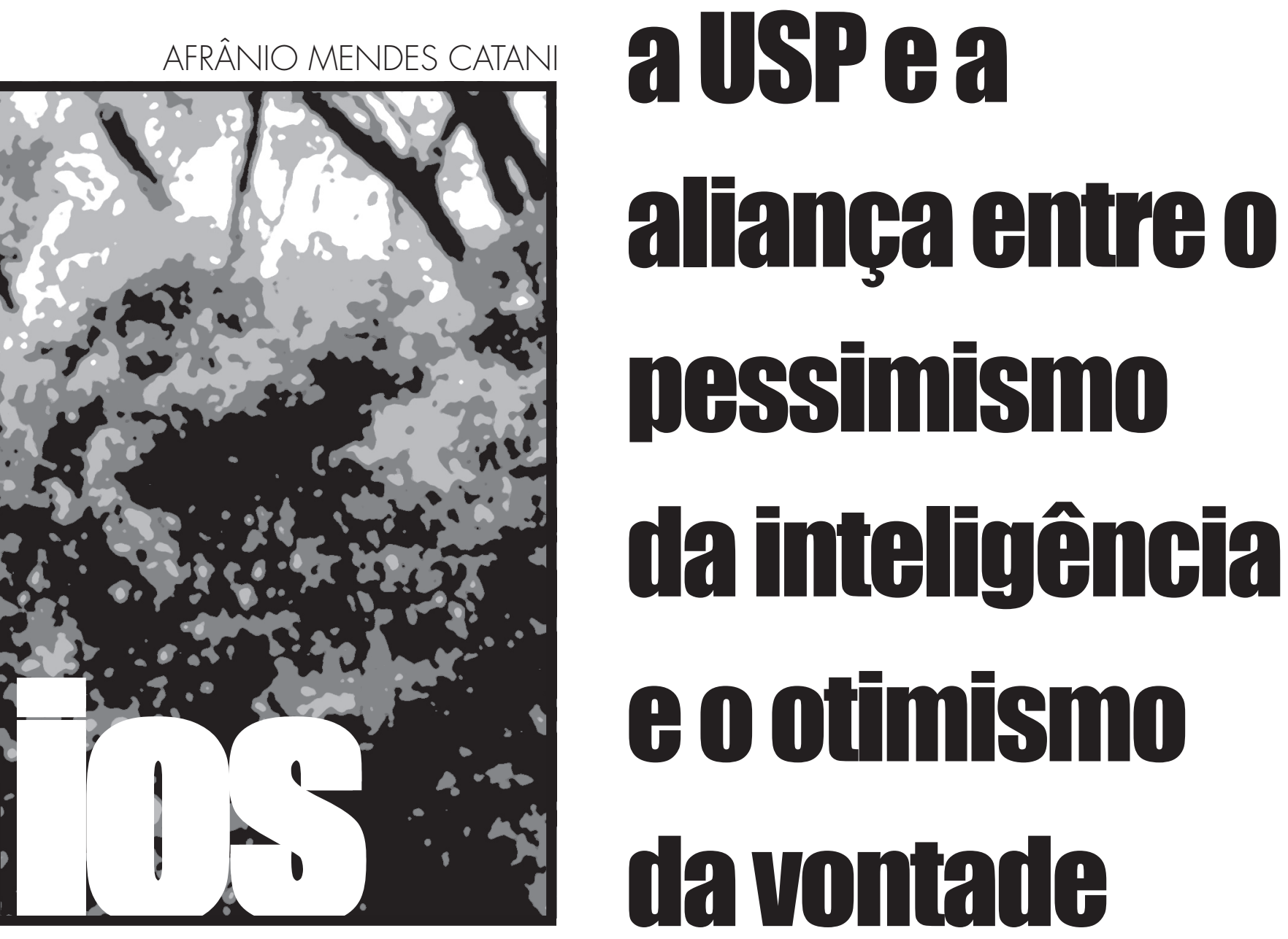

AFRÂNIO MENDES

CATANI é professor na

Faculdade de Educação da

Universidade de São Paulo

(FE-USP) e no Programa

de Pós-Graduação em

Integração da América

Latina (Prolam-USP).
Agradeço a Renato de Sousa Porto

Gilioli pela colaboração. 


\title{
"Em matéria
}

\section{de ciências}

\author{
nenhuma
}

\section{lentidão}

\section{é suficiente;}

\section{em matéria}

\section{do prático,}

\author{
não se pode
}

\author{
esperar"
}

\section{(Mauss, 1969,}

$$
\text { p. 579). }
$$


des do estado de São Paulo. O total de cursos em nível de graduação está ao redor de 160 , enquanto os de pós-graduação (mestrado e doutorado) ultrapassam a casa das cinco centenas. Apesar de insuficiente, há amplo programa de atendimento à comunidade e, também, envolvendo as mais variadas atividades de extensão. O total de servidores não-docentes supera os $14 \mathrm{mil}$, o número de docentes, no final de 2002, era de 4.884. Os alunos são cerca de 65 mil (graduação: 42.500; pós-graduação: 23.000).

Algumas breves considerações devem ser feitas envolvendo alunos e docentes. Quanto ao corpo discente, em nível de graduação (2002), contava-se com 42.500 matrículas (2), sendo que oito unidades concentravam quase 27.000 alunos, correspondendo a $63,50 \%$ desse total. O detalhamento é o seguinte: Faculdade de Filosofia, Letras e Ciências Humanas: 10.190 alunos; Escola Politécnica: 4.530; Faculdade de Economia, Administração e Contabilidade: 3.073; Faculdade de Direito: 2.473; Escola de Comunicações e Artes: 2.021 ; Escola Superior de Agricultura "Luiz de Queiroz": 1.599; Instituto de Matemática e Estatística: 1.556; Instituto de Física: 1.551.

Hegemônica no que se refere ao número de grupos de pesquisa cadastrados junto ao CNPq, a USPé a terceira classificada no quesito total de alunos em nível de graduação. $O$ interessante a ser observado é a grande disparidade entre o número de alunos e o "volume" de investigação acadêmica, particularmente em relação às universidades particulares recém-chegadas ao mercado de ensino.

Com relação a seu quadro docente a USP possuía, em fins de 2002, 4.884 professores, assim distribuídos: Regime de Dedicação Integraçãoà Docência e à Pesquisa (RDIDP): 3.782 (77,50\%); Regime de Turno Completo (RTC): 797 (16,25\%); Regime de Tempo Parcial (RTP): 305 (6,25\%). O total de docentes alcançou o seu ápice em 1990, quando 5.672 professores trabalhavam na instituição. No começo da década passada iniciou-se um processo de "enxugamento" de

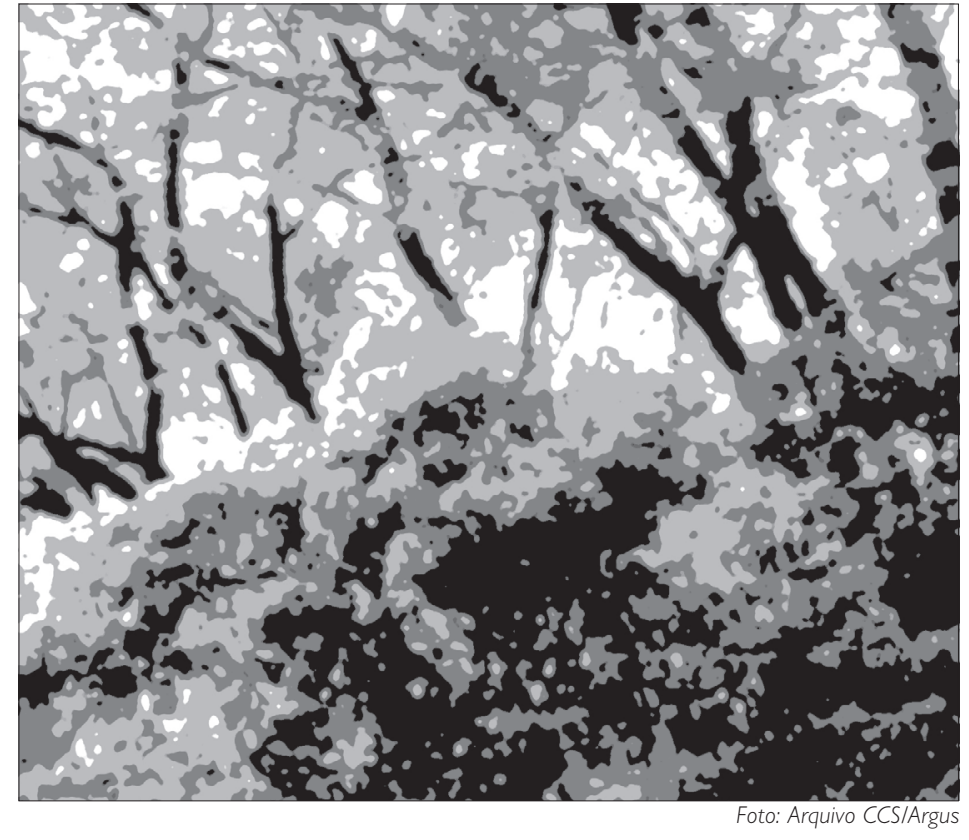

pessoal - ocorrido também na Unicamp , levando à drástica redução da categoria: 1993 (5.375); 1994 (5.310); 1995 (5.056); 1996 (4.971); 1999 (4.728); 2000 (4.694); 2001 (4.755) (Cf. Catani \& Gutierrez, 1998, pp. 128-31; Anuário USP 2002). Dos 4.884 docentes que trabalhavam na USP em 2002 , $59 \%$ concentravam-se em doze unidades, a saber: Escola Politécnica (471), FFLCH (362), Faculdade de Medicina (344), Faculdade de Medicina de Ribeirão Preto (260), Esalq (225), Escola de Engenharia de São Carlos (205), FEA (188), ECA (181), Instituto de Matemática e Estatística (177), Instituto de Física (156), Instituto de Ciências Biológicas (156) e Faculdade de Odontologia (155). O número de professores também é expressivo na Faculdade de Direito (128), na Faculdade de Arquitetura e Urbanismo (132), na Faculdade de Ciências Farmacêuticas (84), na FFCL de Ribeirão Preto (122), na Faculdade de Saúde Pública (96), na Faculdade de Educação (107), no Instituto de Química (107), no Instituto de Psicologia (87), na Escola de Enfermagem (82), na Faculdade de Medicina Veterinária e Zootecnia (92), no Instituto de Botânica (86) e na Faculdade de Odontologia de Ribeirão Preto (88).

Há que se mencionar, ainda, a dimensão orçamentária e a concentração do poder junto aos órgãos centrais da adminissuas origens, dentre outros, Cardoso (1982); Miceli(1989 - especialmente os artigos de Miceli e de Limongi|

2 Inexplicavelmente, na tabela apresentada a seguir, que correlaciona Instituição de Ensino Superior, número de alunos e número de grupos de pesquisa (ranking CNPq), transcrita da Folha de S. Paulo ICaderno Sinapse, 25 de fevereiro de 2003, p. 51, a partir de dados do MEC/Inep e do CNPq, o total de matrículas da USP em seus cursos de graduação é de 35.493
Ver, sobre a criação da USP e 


\section{A PESQUISA NAS 20 MAIORES IES \\ (INSTITUIÇÕES DE ENSINO SUPERIOR) - NÍVEL DE GRADUAC̣ÃO}

Instituição

1 - Universidade Paulista (Unip)

2 - Universidade Estácio de Sá (Unesa)

3 - Universidade de São Paulo (USP)

4 - Universidade Luterana do Brasil (Ulbra)

5 - Universidade do Vale do Rio dos Sinos (Unisinos)

6 - Pontifícia Universidade Católica de MG (PUC-MG)

7 - Universidade Federal do Pará (UFPA)

8 - Universidade do Vale do Itajaí (Univali)

9 - Universidade Federal do Rio de Janeiro (UFRJ)

10 - Pontifícia Universidade Católica do RS (PUC-RS)

11 - Universidade Bandeirante de São Paulo (Uniban)

12 - Universidade Presbiteriana Mackenzie (UPM)

13 - Univ. Est. Paulista Júlio de Mesquista F. (Unesp)

14 - Universidade de Caxias do Sul (UCS)

15 - Universidade Salgado de Oliveira (Universo)

16 - Centro Universitário da Cidade (UniverCidade)

17 - Universidade Católica de Goiás (UCG)

18 - Universidade Federal Fluminense (UFF)

19 - Universidade Federal da Paraíba (UFPB)

20 - Pontifícia Univ. Católica de Campinas (Puccamp)
№ de alunos

Ranking CNPq

(no de grupos de pesquisa)

81.459

$156^{\circ}(14)$

60.067

$1410(16)$

35.493

1으 (1.350)

33.126

290 (144)

31.088

$35^{\circ}(108)$

30.884

27.630

78 ( $(39)$

280 (145)

26.432

$48 \circ(82)$

25.379

2o $(750)$

24.762

15o (210)

24.258

NC*

24.075

690 (48)

23.209

4 (593)

22.900

560 (63)

21.990

1940 (9)

21.841

NC*

21.529

83으 (38)

20.933

$12^{\circ}(236)$

20.724

9० (265)

19.560 $58^{\circ}(61)$

*Nada consta

Fonte: MEC/INEP e CNPq (Sinapse, Folha de S. Paulo, 25 de fevereiro de 2003).

tração universitária. Acredito que o caso da USP seja significativo a respeito. $O$ Anuário Estatístico USP 2002 tem um capítulo dedicado à execução orçamentária por unidade. Um rápido exame desses dados indica a grande concentração de recursos financeiros em órgãos cujos ocupantes máximos foram nomeados pelo reitor ou por sua influência direta. Apenas à Reitoria se destinou percentual de $4,81 \%$ do Orçamento, isto é, montante bem superior ao que receberam algumas unidades de larga tradição em ensino e pesquisa. Senão, vejamos: Escola Politécnica - 4,43\%; Fa- culdade de Medicina - 3,82\%; Faculdade de Medicina de Ribeirão Preto - 3,84\%; Escola Superior de Agricultura "Luiz de Queiroz" - 4,10\%; Faculdade de Direito1,24\%; Instituto de Física-2,47\%; Instituto de Ciências Biológicas - 2,62\%; Escola de Engenharia de São Carlos - 2,76\%. Por outro lado, a Escola de Comunicações e Artes recebeu 2,19\%, a Faculdade de Educação 1,66\%, a Faculdade de Arquitetura e Urbanismo 1,36\%, o Instituto de Psicologia 1,04\%, a Faculdade de Filosofia, Ciências e Letras de Ribeirão Preto 1,45\%, a Faculdade de Economia, Administração e 
Contabilidade 2,07\%, a Faculdade de Saúde Pública 2,14\%, a Faculdade de Odontologia $1,63 \%$ e a Faculdade de Filosofia, Letras e Ciências Humanas 5,14\%.

Os demais "Órgãos Centrais de Direção e Serviços" receberam 8,02\% do Orçamento que, agregados aos já mencionados $4,81 \%$ da dotação da Reitoria, perfazem um total geral de 12,83\%. Além disso, os "Hospitais e Serviços Anexos" (8,90\%), bem como os quatro museus $(1,28 \%)$, parte dos "Centros e Institutos Especializados" $(1,59 \%)$, das "Atividades Integradas" $(5,34 \%)$ e dos projetos especiais $(3,85 \%)$ engrossam a lista.

Em suma, praticamente a terça parte da execução orçamentária da USP para o ano de 2002 ( $\mathrm{R} \$ 1.380 .506 .134,00$ ) foi controlada diretamente pelo reitor (3).

A partir de 1989, as três universidades do estado de São Paulo - a USP, a Unicamp (Universidade Estadual de Campinas) e a Unesp (Universidade Estadual Paulista “Júlio de Mesquita Filho”) - passaram a gozar de autonomia de gestão financeira: “do total do ICMS arrecadado, 25\% vão para os municípios e $1 \%$ para a habitação. Os restantes $74 \%$ são chamados a quota-parte do Estado". Assim, às universidades se destinam, por decreto, 9,57\% dessa quota-parte, o que dá 7,08\% do ICMS total (cf. Fórum das seis entidades, 1994). A trajetória do percentual desse repasse foi a seguinte: $8,4 \%$ (1989, 1990, 1991); 9,06\% (1992, 1993, 1994) e $9,57 \%$ a partir de 1995 . Tais percentuais foram aprovados pela Assembléia Legislativa do Estado de São Paulo por ocasião das votações, realizadas anualmente, da Lei de Diretrizes Orçamentárias (LDO). Atualmente, o total do ICMS é assim distribuído entre as Universidades: USP - 5,0295\%; Unicamp - 2,1958\%; Unesp - 2,3447\% (cf. Catani e Gutierrez, 1998, p. 119).

A USP continua a diferenciar-se consideravelmente do conjunto das Instituições de Ensino Superior brasileiras, embora se torne impossível compreender sua real situação sem que se recupere, ainda que em rápidas tintas, o quadro geral da educação superior no país ao menos a partir de meados dos anos 90 (4).
A reforma da educação superior no Brasil, iniciada a partir dos governos Fernando Henrique Cardoso (1995-2002), sinaliza, até o presente momento, mudanças estruturais ao menos em três esferas gerais: na lógica de expansão e de controle do sistema; na articulação das instituições com as demandas e exigências do mercado e o capital produtivo; nas identidades e finalidades das IES, particularmente das universidades públicas. "As políticas implementadas procuravam alterar, sobretudo, a gestão universitária, o padrão de financiamento, a avaliação (das instituições, dos cursos e dos professores), os parâmetros curriculares de formação dos profissionais, a avaliação e a produtividade dos programas de pós-graduação, o trabalho docente, o relacionamento da universidade com as empresas, dentre outros" (Dourado, Catani \& Oliveira, 2003c). Os elementos privilegiados nas políticas implementadas na última década são constitutivos da gestão e da organização do trabalho acadêmico, permitindo certo ajustamento das IES à lógica da reforma - embora, ao longo do processo, tenham ocorrido tensões, resistências e adaptações que podem ser identificadas em cada uma das áreas que sofreram alterações e que agora, no governo Lula, ganham maior destaque. Nesse sentido, torna-se fundamental "analisar se as políticas de educação superior no atual governo apontam para uma reafirmação das bases da reforma implementada nos últimos anos ou se buscam desconstruíla, colocando o sistema de educação superior em outra direção" (Dourado, Catani \& Oliveira, 2003c).

A política de diversificação e de diferenciação foi a base da reforma operada no governo FHC, associando três princípios fundamentais: flexibilidade, competitividade e avaliação, com o objetivo de levar a uma expansão acelerada do sistema. O modelo idealizado diversificou e diferenciou as IES e os cursos de nível superior ofertados, visando, também, romper com o modelo único que vinha sendo constituído a partir da reforma universitária de 1968 e que tinha a universidade como instituição-
3. No Anuário Estatístico da USP 2002 há uma tabela intitulada "Liberações Financeiras do Tesouro do Estado de São Paulo para a USP - 1996 a $2002^{\prime \prime}$ onde se pode ver que o montante repassado atingiria $\mathrm{R} \$$ 1.404.624.697.00. Há igualmente, a seguinte obser vação: "Em 2002 foram liberados recursos suplementares no valor adicional de $R \$$ 11.359.100,00 referente ao Programa de Expansão do Ensino Superior

4 resgate desse quadro gera será realizado, fundamentalmente, através dos seguintes rabalhos: Catani \& Oliveira (2002a, 2002b, 2003) Catani, Oliveira \& Dourado (2002): Dourado, Catani \& Oliveira $(2003 a, 2003 b$ 2003c); Trindade (1998) 
referência para a expansão de vagas. Procurou, também, romper com elementos centrais de convergência que asseguravam certo nível de solidariedade entre as Instituições Federais de Ensino Superior (Ifes), tais como: "indissociabilidade ensino-pesquisa-extensão, gestão democrática, padrão universitário de qualidade, carreira unificada, avaliação institucional”. Um dos objetivos centrais da reforma "foi a efetiva separação entre ensino e pesquisa a partir, sobretudo, de mudança na organização acadêmica e na formação de profissionais para o mercado de trabalho" (Dourado, Catani \& Oliveira, 2003c; ver, também, Catani \& Oliveira, 2002a e 2002b).

Já em 2001, com o crescimento acelerado da oferta, o setor privado respondia por $67 \%$ das matrículas em cursos de graduação. A enumeração dos principais mecanismos de expansão da educação superior e das políticas adotadas no período detalham as observações realizadas até o momento, sendo que dentre as medidas mais significativas encontram-se as seguintes:

a) criação de centros universitários, com autonomia para o desenvolvimento de atividades na área de ensino e formação profissional;

b) criação, regulamentação e consolidação dos cursos seqüenciais, isto é, cursos de nível superior de curta duração voltados para uma formação profissional específica ou para a complementação de estudos, como alternativa ao acesso da sociedade ao ensino de $3^{0}$ grau;

c) criação, regulamentação e consolidação dos cursos tecnológicos, a serem ofertados sobretudo nos centros de educação tecnológica, que visam dar uma formação profissional mais estrita e afinada com as demandas tecnológicas das empresas e do mercado de trabalho;

d) flexibilização curricular, que procurou adequar os cursos de graduação às demandas do mercado de trabalho;

e) instituição e consolidação do Exame Nacionaldo Ensino Médio(Enem), que tem por finalidade básica diversificar o processo de acesso ao ensino superior, oferecen- do alternativa(s) de associação ou substituição do vestibular;

f) incentivo aos programas de ensino a distância, os chamados cursos virtuais, incluindo os cursos de graduação;

g) criação, regulamentaçãoe implementação dos chamados Institutos Superiores de Educação, que abrigam o curso normal superior e os demais cursos de licenciatura sobretudo fora das universidades;

h) adoção do Exame Nacional de Cursos - ENC (Provão) como parâmetro para a expansão automática de vagas, como forma de premiar os cursos considerados A ou B e também como meio de controle para justificar o processo de flexibilização e agilização na criação de cursos e de IES privadas;

i) definição de nova matriz de distribuição de recursos orçamentários (entre as Ifes) que privilegiou o número de alunos efetivos na graduação, em detrimento das atividades de pesquisa e de extensão (Dourado, Catani \& Oliveira, 2003c).

As políticas de diversificação e diferenciação da educação superior implementadas acentuaram, portanto, pressupostos fundamentais do projeto neoliberal em curso em praticamente toda a América Latina. Assim sendo:

a) buscaram favorecer a concorrência e $\mathrm{o}$ atendimento às diferentes demandas e clientelas, mediante oferta que promoveu a dissociação entre ensino e pesquisa;

b) procuraram naturalizar ainda mais as diferenças individuais, instituindo paulatinamente um sistema que contemplasse essas diferenças em termos de capital econômico, cultural e social acumulado;

c) ampliaram a subordinação do ensino superior ao mercado, particularmente no tocante à formação profissional e à produção de bens e serviços acadêmicos;

d) explicitaram mais a forma de funcionamento do sistema do que as suas finalidades sociais e o seu compromisso com o bem-estar coletivo e com o projeto de nação;

e) deram ao Estado os instrumentos legais e burocráticos necessários à avaliação, 
supervisão e controle, o que permitiu promover uma maior competitividade no sistema (Catani \& Oliveira, 2002).

Aprovado no final de 2001, o Plano Nacional de Educação (PNE) acabou reafirmando, em grande medida, a política que vinha sendo implementada e que deveria nortear a reestruturação da educação superior no país nos dez anos que se seguissem ao Plano. Por meio do diagnóstico, diretrizes e, em especial, dos objetivos e metas constantes do item "educação superior", onde se observam os vetos presidenciais, é possível verificar que a política governamental na área busca uma expansão acelerada por intermédio da diversificação e diferenciação da oferta, do crescimento das matrículas no setor privado e da racionalização dos recursos nas Ifes, que permita ampliação de vagas a custo zero, sobretudo nas universidades federais. Objetiva-se também maior articulação dos currículos de formação com as demandas do mercado e maior controle da educação superior, por meio de uma lógica de avaliação estandardizada, que ordene as tomadas de decisão em termos de gestão e do estabelecimento de políticas governamentais (Catani \& Oliveira, 2003).

Os vetos de FHC ao PNE, sobretudo no tocante ao financiamento da educação, consubstanciou ainda mais o processo de mercantilização da educação superior em curso no país; eliminou aportes financeiros para garantir o aumento da oferta de vagas no setor público, apesar de ter como meta a efetivação da expansão pública a custo zero; induziu as Ifes, em geral, a assumirem perfil mais empresarial quanto à obtenção de recursos financeiros adicionais para sua manutenção e desenvolvimento. Nesse sentido, concordamos com Silva Jr. \& Sguissardi (2001, p. 272), quando analisam que sob a atuação do governo FHC " as novas faces da educação superior no Brasil não parecem [...] garantir um avanço significativo da educação pública e da inclusão social, ao contrário, tenderiam a aprofundar a apartação social entre a minoria incluída e a maioria dos cada vez mais ex- cluídos da sociedade da informação ou do conhecimento".

É preciso destacar que os primeiros gestos do MEC, a partir do início do governo Lula, indicam preocupação no sentido de discutir o papel, a natureza e os compromissos que a universidade pública deverá assumir na formulação de projeto de desenvolvimento do país, sobretudo no que tange à resolução de problemas sociais e de formação de recursos humanos e geração de conhecimento que possam contribuir efetivamente para o crescimento da nação (Dourado, Catani \& Oliveira, 2003c).

A implementação das políticas para a educação superior tem, contraditoriamente, ensejado poucas mudanças. Tal situação tem revelado um descompasso entre o preconizado no plano de governo e os limites para a sua efetivação. Tais limites devem-se, entre outros, à lógica macroeconômica adotada pelo governo federal, ao contingenciamento resultante de um orçamento já aprovado pela gestão anterior, por contratos já estabelecidos visando garantir a organicidade das políticas que traduziam a lógica vigente (Provão, Enem e outros) e pelo descompasso entre algumas ações das diversas secretarias e órgãos que compõem o Ministério da Educação que parecem não expressar uma organicidade das políticas resultando, ao contrário, num cenário de pulverização das ações.

Neste cenário, é oportuno situar o programa Toda Criança Aprendendo proposto pela Secretaria de Ensino Fundamental do MEC que, ao propor uma política de certificação docente, desconsiderou os esforços do MEC no sentido de repensar a lógica de avaliação meritocrática herdada. Outro contorno importante refere-se às ações de expansão da educação superior por meio da modalidade a distância que parece ganhar centralidade no atual governo e não tem se convertido em ação orgânica entre a Seed e a SESu. Outro dado importante refere-se à pouca centralidade das ações e políticas no tocante à educação superior por parte do Ministério (Dourado, Catani \& Oliveira, 2003c).

Das ações efetivadas para a educação 
superior merece particular destaque a designação de uma Comissão Especial de Avaliação, composta de intelectuais comprometidos com a temática, "com a finalidade de analisar, oferecer subsídios, fazer recomendações, propor critérios e estratégias para a reformulação dos processos e políticas de avaliação da educação superior e elaborar a revisão crítica dos seus instrumentos, metodologias e critérios utilizados". O trabalho da referida comissão pautou-se por uma

“visão abrangente do papel dos processos avaliativos sem dissociar estes da necessária regulação do Estado para fomentar e supervisionar o sistema em seu conjunto, mas também reconhece a importância de uma política capaz de refundar a missão pública do sistema de educação brasileiro, respeitando sua diversidade, mas tornando-o compatível com as exigências de qualidade, relevância social e autonomia. Partindo do princípio de que a educação é um direito e um bem público, entende que a missão pública da Educação superior é formarcidadãos, profissional e cientificamente competentes e, ao mesmo tempo, comprometidos com o projeto social do país" (Brasil, MEC, 2003, p. 7).

Tal concepção revelou um esforço em repensar as políticas estandardizadas para o setor, bem como a lógica restritiva imposta ao campo universitário ao reduzi-lo à mera subordinação ao mercado de trabalho. Após audiências públicas, com o objetivo de ampliar as bases analíticas dos processos de gestão e regulação da educação superior, a comissão propôs um Sistema Nacional de Avaliação da Educação Superior, entendendo-o como base para uma nova proposta de avaliação da educação superior brasileira pautada pelos seguintes princípios e critérios: educação como direito social e dever do Estado, definição de valores sociais historicamente determinados, rediscussão dos atuais marcos de regulação e controle ampliando o seu escopo para o Estado e a comunidade educativa; resgate histórico e político do caráter edu- cativo e, portanto, formativo da avaliação; respeito à identidade e à diversidade institucionais em um sistema diversificado e globalidade, legitimidade e continuidade das ações de avaliação no sentido de garantir eficácia formativa e efetividade social por meio da regulação com a emancipação institucional (Brasil, MEC, 2003, pp. 63-8).

A questão que parece central nesse processo, no contexto atual, é perceber, como afirma Chauí (1998), que a luta democrática e republicana está demarcada agora pela luta pelo Fundo Público. Nesse sentido, o Fundo Público pode voltar-se mais efetivamente para o atendimento de demandas e carências da população em geral ou pode voltar-se às demandas e exigências relacionadas aos que possuem acúmulo de capital. A demanda pelos recursos do Fundo Público, mediada pelo Estado, expressa a luta histórica entre a classe-que-vive-docapital e a classe-que-vive-do-trabalho, levando em conta a constituição dos Estados-nação e a consolidação do modo de produção capitalista. Existe, portanto, uma enorme tensão quando se decide, nos poderes Executivo e Legislativo, sobre a destinação dos recursos públicos, pois há que se fazer uma opção: financiam-se ações na linha que propicia a acumulação de capital ou na perspectiva que favorece a reprodução e a emancipação crescente do trabalho (Dourado, Catani \& Oliveira, 2003c).

Conforme Amaral, Catani e Oliveira (2003), é nesse contexto que se torna fundamental analisar e discutir o financiamento da educação superior brasileira, considerando as mudanças em curso e os desafios da luta democrática pela destinação do Fundo Público. É preciso ter claro, inicialmente, que os recursos financeiros destinados ao ensino superior público brasileiro pertencem ao Fundo Público e que o seu volume sujeita-se a tensões ideológico-econômicas. Fazse necessário, conforme expressam os autores, considerar essa temática levando em conta a estrutura capitalista-liberal e o recente processo de reforma do Estado no Brasil, bem como as mudanças que vêm ocorrendo no campo da educação superior, sobretudo nas últimas três décadas. 
É fundamental, portanto, aprofundarmos o debate acerca do financiamento público da educação superior brasileira e do papel social dessa frente ao contexto econômico, político e cultural que se quer construir. A dialética mais geral da função do Fundo Público, no que se refere à reprodução do capital e da força de trabalho, também se aplica à educação superior. A desmercantilização das IES públicas, como contraponto às políticas implementadas na última década, constitui-se imperativo nas opções a serem estabelecidas para a utilização do Fundo Público. Faz-se necessário também demarcar, de maneira mais clara, como o país vai utilizar e distribuir a riqueza pública produzida e como vai estabelecer as formas de controle institucionais desses recursos. Sem essa alteração no relacionamento Estado-universidades públicas ou educação superior pública torna-se impossível reverter o processo de privatização, mercantilização e mercadorização que pautou a reestruturação a partir da década de 1990 (Dourado, Catani \& Oliveira, 2003c).

Retomando o que afirmei em páginas anteriores, a USP (docentes, alunos, funcionários) não se encontra em uma redoma, isolada em suas excelências e produtividades inquestionáveis. Acredito ser redundante e cansativo reiterar suas virtudes institucionais, sua contribuição como geradora e difusora de conhecimento e locus de formação de quadros nos mais distintos matizes. O que está em jogo, acredito, é uma outra dimensão (5), que recupero a partir de texto anterior (Catani, 2003c, p. 256). Escrevi o seguinte:

"Hélgio Trindade, valendo-se de um texto de J. J. Brunner e G. Sunkel (Conocimiento, sociedad y política. Santiago, Flacso, 1993, p. 9-15), pondera que, ao menos no que se refere às ciências ditas humanas, alguns especialistas diagnosticam que os pesquisadores sociais, recolhidos em seus domínios tradicionais de produção departamentos ou centros de pesquisa -, encontram-se cada dia em maior desvantagem em relação aos 'analistas simbólicos'. Estes cumprem as mesmas funções em novos domínios (consultorias privadas, assessoria legislativa, agências de análise e organismos internacionais) e estão 'constituindo um sistema que se parece cada vez mais com um contexto de mercado'. Apoiando-se no conhecimento disponível das ciências sociais, o que interessa ao analista simbólico 'é, sobretudo, o serviço que manipula, operando os efeitos plásticos buscados'. Neste novo contexto de 'globalização do mercado de analistas simbólicos', criam-se 'novas formas de financiamento em expansão', tornando obsoletas as que "no passado permitiam o desenvolvimento das universidades"'.

Esse é o ponto. O trabalho acadêmico realizado de forma tradicional tende a ser estigmatizado em detrimento de formas mais "dinâmicas", de aplicações imediatas. Bourdieu escreve que, para se avançar além das manifestações aparentes, há que se evitar aquilo em que o mundo intelectual se transformou, isto é,

"o terreno de uma luta visando produzir e impor 'novos intelectuais', portanto uma nova definição do intelectual e do seu papel político, uma nova definição da filosofia e do filósofo, doravante empenhado nos vagos debates de uma filosofia política sem tecnicidade, de uma ciência social reduzida a uma patologia de sarau eleitoral e a um comentário descuidado de pesquisas comerciais sem método. Platão tinha uma palavra magnífica para todas essas pessoas, doxósofo: esse 'técnico-da-opinião-que-secrê-cientista' (traduzo o triplo sentido da palavra) apresenta os problemas da política nos próprios termos em que os apresentam os homens de negócios, os políticos e os jornalistas políticos (isto é, exatamente os que podem pagar pesquisas...) [...]. O sociólogo se opõe ao doxósofo, como o filósofo, porque questiona as evidências e sobretudo as que se apresentam sob a forma de questões, tanto as suas quanto as dos outros [...]. O que defendo acima de tudo é a possibilidade e a necessidade do intelectual crítico, e principalmente crítico da doxa intelectual que os doxósofos difun-

\footnotetext{
Não retomo aqui diretamen te, por falta de espaço, uma série de questões candentes, tais como a educação como direito social e as perspectvas de universalização do acesso do ensino superior gra tuito Iver, a respeito: Olive ra, Moehlecke \& Catani 2003); o debate acerca do relacionamento da USP e das fundações (entidades priva das de apoiol - há vasto material editado pela Associação dos Docentes da USP (Ádusp), que está sendo obje to de investigação que ape nas começo a realizar no momento; os cursos pagos minis trados no inteiro dos seus campi, sob as mais variada modalidades; as alarmantes taxas de evasão escolar; a total insegurança nos campi e a inútil atuação das empresas terceirizadas de prestação de serviços de segurança, etc.
} 
dem. Não há verdadeira democracia sem verdadeiro contra-poder crítico. O intelectual é um contra-poder, e de primeira grandeza. É por isso que considero o trabalho de demolição do intelectual crítico, morto ou vivo-Marx, Nietzsche, Sartre, Foucault, e alguns outros classificados em bloco sob o rótulo de 'pensamento 68 ' -, tão perigoso quanto a demolição da coisa pública e inscrevendo-se no mesmo empreendimento global de restauração" (Bourdieu, 1998,pp. 16-8; Bourdieu, 1997, pp. 733-6) (6).

Bourdieu, no início dos anos 90, criou a revista Líber - "revista internacional de livros" (o número inaugural é de março de 1990) -, representando a aproximação em relação a intelectuais de áreas próximas ou mesmo distantes das ciências sociais, como por exemplo os matemáticos. "Tais alianças e aproximações como que antecipam a mesma concepção generosa das humanidades que está na raiz da revista [...], tentativa bem-sucedida de financiar uma aliança entre as Letras, a Filosofia, as Artes e as Ciências Sociais" (Miceli, 1999, p. 115). Com a Líber, encabeçada por Bourdieu, pretendia-se estabelecer uma forma de resistência a uma situação de "ajuste intelectual", propondo "uma retomada do Iluminismo que passa pelo resgate da capacidade de aliar autonomia da esfera intelectual com o engajamento crítico em um espaço público e político. Nesse sentido, redefine o modelo e a 'missão' dos intelectuais. Em lugar do intelectual total à maneira de Sartre, ou do 'intelectual específico’ de Foucault, sugere o 'intelectual coletivo', transdisciplinar e internacional como alternativa aos poderes econômicos, políticos e da mídia” (Musse, 1997) (7). O “intelectual coletivo" seria um conjunto de indivíduos cuja soma de trabalhos de pesquisa e participação em assuntos comuns constitui uma espécie de coletivo ad hoc.

O que se aproxima dessa forma de atuação preconizada por Bourdieu e seus companheiros, no Brasil, talvez seja o "Fórum de Políticas Públicas”, lançado por um coletivo de docentes da USP em 20 de dezembro de 2002 e que agora encontra-se abrigado no Instituto de Estudos Avançados-USP. A publicização do Fórum ocorreu em sessão no auditório da Faculdade de Arquitetura e Urbanismo, congregando mais de 400 pessoas, tendo como mote a seguinte questão: “O que a universidade pode fazer pelo Brasil?"

Os documentos lançados são em número de quatro: os dois preparatórios (dezembro de 2002), o que foi divulgado em janeiro de 2003, bem como o encaminhado ao prof. dr. Gerhard Malnic, então diretor do IEA-USP, em fins do primeiro semestre de 2003.

O primeiro documento, de 5 de dezembro de 2002, intitula-se "Em Cena”. Destaca a necessidade de a universidade brasileira se manter sintonizada com a sua época, principalmente após a vitória de Lula para a Presidência da República. "Contra o espírito de arquipélago, a Universidade pode estimular o diálogo entre disciplinas, a mescla de campos, a síntese de visões, que há muito não cabem nos limites estreitos da velha estrutura departamental [...]". A livre pesquisa e a autonomia acadêmica, tão preciosos quanto ameaçados, são hoje mais do que nunca fundamentais. "Como pesquisadores, o melhor que podemos fazer pelo país é preservar esse patrimônio ameaçado, ampliando-o urgentemente por meio de um esforço simultâneo para dentro e para fora das cidades universitárias." Objetivava-se perseguir dois alvos: a) "constituir uma rede de cumplicidades no interior das Universidades, nos núcleos e centros de pesquisa, é tarefa básica para quem pretende elaborar novas políticas públicas bebendo das fontes das sociologias, físicas, matemáticas, filosofias, economias, engenharias, antropologias, letras e tantas outras áreas do saber. Rede de cumplicidades que saberá encontrar meios e mecanismos de comunicação e intercâmbio. Nesse sentido, serábem-vindo o lançamento e a sustentação de um Portal Público na Internet, como meio oxigenador do debate acadêmico"; b) "a partir da USP, buscar dar forma a partir de um Laboratório de Novas Estratégias Públicas, de modo a institucionalizar o esforço de aglutinação 
humana e a estruturar um espaço de produção sistemático de novas diretrizes para as políticas públicas no Brasil”.

O documento conclui-se com a afirmação de que esses dois objetivos "se complementam no apoio, estímulo, provocação, crítica, animação e socialização do conhecimento de interesse público. Sua independência de partidos políticos e de governos é marca fundante, assim como a democracia de seus laços internos e externos. O movimento que pretendemos lançar deve ser múltiplo, democrático, diversificado, polimorfo e interativo. Trata-se de um padrão de dedicação acadêmica distinto da normalidade universitária. A começar pela idéia-força da agregação em torno da nova dimensão que se abre para a vida pública [...]. Mais do que abertos ao novo, queremos participação envolvimento com toda forma de resistência à erosão das instituições e ao nosso declínio como mulheres e homens públicos".

Lê-se no segundo documento (sem títu1o) que a vitória eleitoral do PT “acontece em uma conjuntura que dificulta ao máximo uma política de transformação social", prevendo que "o governo de Luiz Inácio Lula da Silva será marcado [...] pelo embate entre o anseio de transformação social e as dificuldades para implementá-la". Reconhece com todas as letras que "o programa do novo governo não é um programa socialista. Defende o respeito aos contratos e à propriedade. Trata-se antes de um projeto reformista. Não no sentido das reformas neoliberais da década passada, mas de uma atualização do programa de reformas de base, do governo João Goulart. A diferença é que, enquanto os altos índices de crescimento, alcançados no governo JK, constituíam o ponto de partida dessas reformas (impossibilitadas apenas pelo espírito submisso de nossas classes dominantes e pelo cenário da Guerra Fria), o esforço do novo governo deve ser no sentido de simultaneamente impulsionar o desenvolvimento econômico e as reformas sociais. Ou melhor, parte-se de uma premissa, cada vez mais atual, de que, ao contrário da célebre frase de Delfim Neto - 'é preciso fa- zer o bolo crescer antes de reparti-lo' -, as reformas são uma espécie de pré-condição da retomada do desenvolvimento". Entende que a viabilidade de "um programa alternativo ao neoliberalismo será tentado no Brasil nos próximos anos [...]. A crise econômica mundial fragilizou a hegemonia do neoliberalismo. Mas o êxito ou não de uma política alternativa dependerá da criatividade e da ação das forças sociais envolvidas nesse processo". E conclui, definindo as tarefas para parte dos docentes universitários: "a tarefa dos intelectuais de esquerda, da universidade, nesse cenário, adquire grande importância. Não se trata apenas de interferir na disputa pela hegemonia ideológica. Cabe também constituir e tentar implementar projetos que auxiliem o país a superar o programa neoliberal, com uma intervenção eivada e orientada para a transformação social".

O terceiro documento, "Notas sobre o Fórum de Políticas Públicas" (23 de janeiro de 2003), menciona que o coletivo de intelectuais que havia sido lançado no mês anterior "tem vocação integradora de iniciativas e projetos em gestação e/ou em andamento, sempre respeitando a dinâmica de seus integrantes". Deve constituir-se como um espaço de diversidade, no momento em que o novo governo inicia seu mandato. Propõe-se que vai se buscar estabelecer "um diálogo com a nova administração e com suas políticas. Mas o melhor que a Universidade pode fazer para o país e mesmo para o governo é intensificar a chama da crítica. Se o governo pode errar, como disse o presidente da República, nada melhor do que a reflexão engajada e contundente daqueles que estão compreendendo que o Brasil começou a mudar e que pode mudar muito mais. Dessa forma, a nossa autonomia (na forma e no conteúdo) e o exercício independente da razão é vital para o sucesso de um Fórum de reflexão e elaboração como o nosso".

"Na mesma direção, os laços dos membros do Fórum devem ser muito amplos, flexíveis e, fundamentalmente, democráticos Não somos um partido político nem um 
sindicato, e nem estamos dispostos a fomentar laços de atrelamento a nenhum deles. Não queremos afastar os que desconfiam (ou não simpatizam) do atual governo. O ponto que nos une é a disposição de discutir e elaborar políticas públicas, seja acentuando a crítica, seja acentuando a formulação de alternativas, seja combinando as posturas do modo que cada um, cada grupo, julgar conveniente. Estamos apenas reivindicando o nosso espaço como professores e pesquisadores universitários que estão aceitando o desafio de pensar políticas de um modo razoavelmente mais organizado e com foco do que o laissez-faire que marca necessariamente a vida acadêmica. Para tanto, a democracia, a tolerância, o respeito devem integrar nossos fundamentos para além da retórica trivial".

Nos itens finais, prevê que o Fórum deve

"[...] livrar-se de todas as amarras, preconceitos e fórmulas orgânicas de tipo reivindicativo ou político-partidário. Como um espaço aberto e diverso de discussão franca e respeitosa sobre políticas públicas, deve estimular a formulação da crítica e das alternativas. A Universidade brasileira, e a USP em especial, não pode ficar à margem do que está ocorrendo hoje no País. Se o mote-chave é a mudança, nada melhor do que propor que a parte mais emblemática da inteligência nacional, que domina técnicas, metodologia e que sabe pesquisar, seja capaz de produzir conhecimento para um país que pretende se renovar. Se formos capazes de exercitar nossas capacidades, dando forma a alternativas, outros caminhos (mesmo que cruzados), oportunidades e, principalmente, conhecimento novo sobre a política econômica, o fome zero, a orientação tecnológica, cultural, científica e assim por diante, teremos dado uma enorme contribuição ao País. Para levar a cabo esse debate, sugerimos que seja pensado um colegiado amplo do Fórum, capaz de representá-lo e de dar prosseguimento às suas decisões (Portal na Internet, espaço para uma sede, computador, rede de membros/amigos do Fórum, rede de pesquisadores, estímulo para debates etc.)".

O documento entregue ao prof. Gerhard Malnic (IEA-USP) constitui-se em síntese, com alguns acréscimos e alterações, dos textos anteriores. Assinado por três dezenas de professores de distintas unidades da USP (8), o Fórum de Políticas Públicas “está sendo implementado no espírito de que a Universidade brasileira precisa estar em sintonia

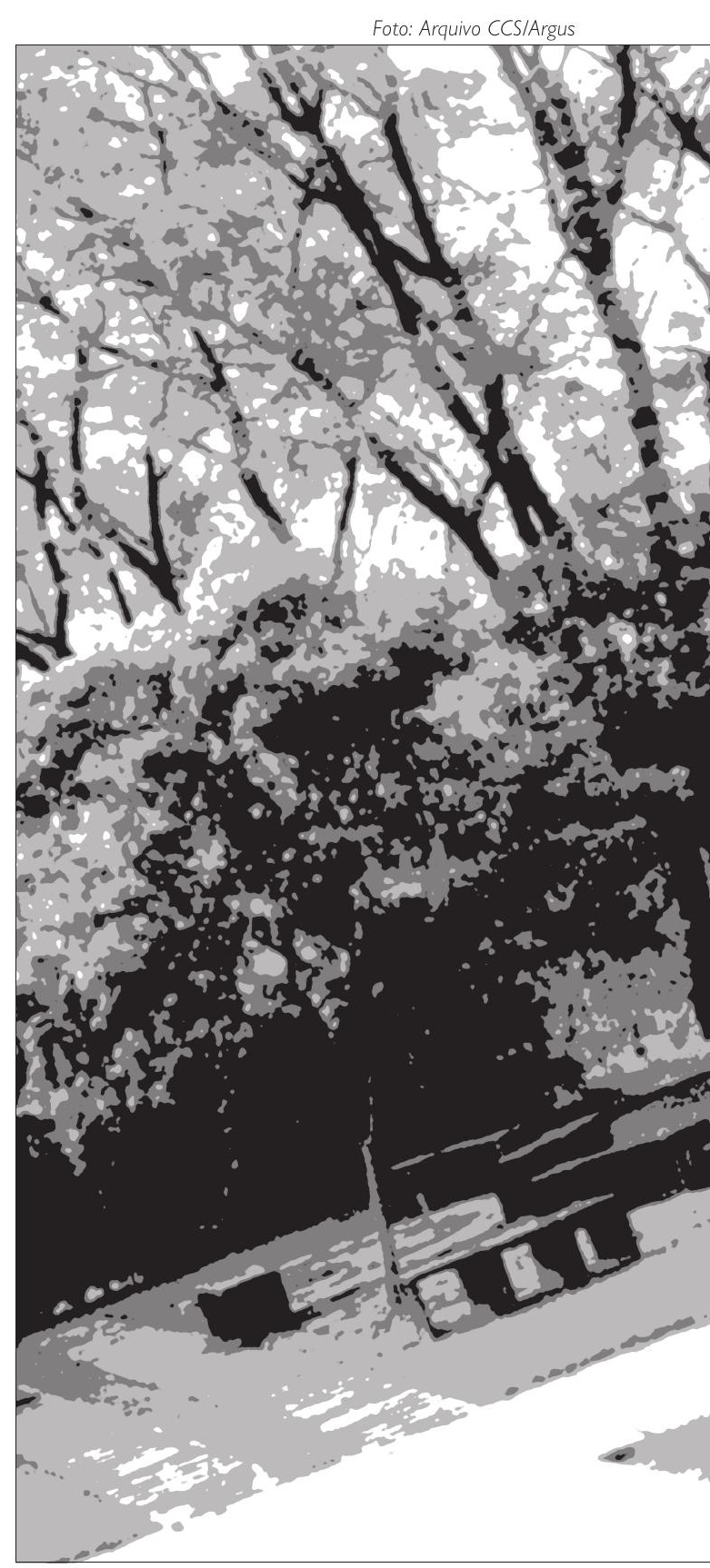


com o espírito de sua época. E isso se faz com trabalho e pesquisa séria, e com a produção permanente de novos conhecimentos". O Fórum foi pensado com o intuito de

"reunir, agregar, combinar, fazer interagir as atividades individuais, projetos coletivos, grupos de pesquisa ou de afinidades profissionais, etc. O ponto de convergência entre as diversas iniciativas e atividades é a disposição para o debate, para a discussão e elaboração de novos parâmetros para as políticas públicas no Brasil, seja acentuando a crítica, seja acentuando a formulação de alternativas, seja combinando as posturas do modo que cada um, cada grupo, julgar conveniente. Trata-se de valorizar e potencializar os conhecimentos e competências acumulados em cada uma das áreas, promovendo a sinergia das iniciativas em torno do debate, da crítica e proposição de alternativas para as questões que se julgar relevantes para os rumos do país. Uma reflexão engajada e comprometida com os desafios do momento, mas que também inove na forma de produção e difusão do conhecimento, incentivando as convergências, as transversalidades, as intersecções entre os vários campos do saber, pavimentando dessa forma as vias para a superação do atual insulamento da vida acadêmica e também das hoje anacrônicas fronteiras disciplinares".

Como espaço democrático de aglutinação dos docentes da USP e do país, "não cabe ao Fórum a definição a priori de uma agenda de debates e atividades. E muito menos se restringir a um ou outro tema posto pelas urgências políticas do momento. A agenda do Fórum será montada a partir da reunião do conjunto das iniciativas que vierem a ser propostas pelos docentes nele engajados. Tanto podem ser agendas temáticas ou definidas em torno de questões determinadas julgadas relevantes para os rumos do país, como também podem ser propostas de consenso construídas nos pontos de intersecção dessas e outras atividades".

O Informativo do Instituto de Estudos
Avançados da Universidade de São Paulo (ano XV, no 72, ago.-set./2003) fez a divulgação do Fórum às páginas 4 e 5 , além de sintetizar os debates ocorridos quando da discussão do primeiro tema do FPP, qual seja, a TV Digital. O Fórum sobre TV Digital “é integrado por pesquisadores e profissionais da USP vinculados à Escola Politécnica, Escola de Comunicações e Artes, TV USP, Escola do Futuro, Faculdade de Filosofia, Letras e Ciências Humanas e Projeto Cidade do Conhecimento (ligado ao IEA)".

Atualmente, colegas discutem o formato de um Fórum envolvendo temas relativos às políticas de ensino superior no Brasil.

Gostaria, nesse momento, de retomar a epígrafe do presente artigo, extraída de um texto de Marcel Mauss, que reflete com precisão os dilemas que a Universidade e seu corpo docente hoje enfrentam. "Em matéria de ciências, nenhuma lentidão é suficiente": isso nos remete à idéia braudeliana da longa duração, das sedimentações constantes e incessantes, próprias da reflexão acadêmica, metódica e sistemática. "Em matéria do prático, não se pode esperar": há que se estar preparado para atender a demandas que necessitam de um saber especializado, qualificado e, por vezes, de ponta.

Pierre Rosanvaillon, em sua aula inaugural no Collège de France, no ano passado, intitulada "Por uma História Conceitual do Político", recupera as considerações de Mauss e pondera que se trata de "problemas contemporâneos universalmente debatidos", sendo "muito grande o risco de ver desaparecer a diferença entre o trabalho paciente e o comentário apressado, em uma palavra, entre a ciência e a opinião" (Rosanvaillon, 2003, p. 77).

Navegando por águas que conhece bem, entende que a história moderna e contemporânea do político "não saberia desentender-se do mundo e encerrar-se em um recinto preservado pelo inacessível aos movimentos da vida. Ao contrário, sua ambição é descer à arena cívica e trazer para ali um suplemento de inteligibilidade, um aumento de lucidez. Deve propor uma leitura 
crítica e serena do mundo nos locais em que dominam com tanta frequiência o clamor das paixões, a versatilidade das opiniões e a comodidade das ideologias. Portanto, o trabalho científico mais rigoroso e as aquisições mais pertinentes da erudição participam diretamente da atividade cidadã, nascem da confrontação com o acontecimento e permanecem ligados a ele" (Rosanvaillon, 2003, pp. 77-8).

Conluo valendo-me, uma vez mais, do historiador francês, que procura pautar seu trabalho no exemplo dos grandes sábios, “que o foram também, por sua própria obra, infatigáveis cidadãos e que não se deram trégua em esposar o pessimismo da inteligência com o otimismo da vontade, para retomar uma expressão de Romain Rolland, popularizada por Gramsci, que serviu durante muito tempo de guia a uma grande parte de minha geração" (Rosanvaillon, 2003, p. 78).

\section{BIBLIOGRAFIA}

AMARAL, Nelson Cardoso; CATANI, Afrânio Mendes, OLIVEIRA, João Ferreira de. “0 Financiamento Público da Educação Superior Brasileira: Mudanças e Desafios", in Revista Brasileira de Política e Administração da Educação. São Paulo, Anpae, 2003 (no prelo).

ANUÁRIO ESTATíSTICO USP 2002. São Paulo, RUSP (Reitoria da Universidade de São Paulo), 2002 (http:// sistemas.usp.br/anuario, consulta realizada em 16/9/2003).

BOURDIEU, Pierre (coord.). A Miséria do Mundo.Trad.: vários. Petrópolis, Vozes, 1997.

BOURDIEU, P. Sur la Télévision. Paris, Raisons d’Agir Éditions, 1997.

. Contrafogos: Táticas para Enfrentar a Invasão Neoliberal. Trad.: Lucy Magalhães. Rio de Janeiro, Jorge Zahar, 1998.

Contre-feux 2: pour um Mouvement Social Européen. Paris, Raisons d'Agir Éditions, 2001.

Pensamento y Acción. Trad.: Octavio Kulesz. Buenos Aires, Libros del Zorzal, 2002.

BRASIL. Ministério da Educação. Sistema Nacional de Avaliação da Educação Superior - Sinaes. Brasília, MEC, 2003.

CALLINICOS, Alex. "Testando a Teoria Social através da Política: Pierre Bourdieu e Anthony Giddens", in Margem Esquerda - Ensaios Marxistas (no 2). São Paulo, Boitempo Editorial (no prelo).

CARDOSO, Irene A. Ribeiro. A Universidade da Comunhão Paulista. São Paulo, Cortez/Autores Associados, 1982.

CATANI, Afrânio Mendes. "Pierre Bourdieu e a Formulação de uma Teoria Social que Procura Revelar os Fundamentos Ocultos da Dominação", in Heloisa Turini Bruhns; Gustavo Luis Gutierrez (orgs.). 0 Corpo e o Lúdico: Ciclo de Debates Lazer e Motricidade. Campinas, Autores Associados, 2000, pp. 53-65.

"Miséria e Sofrimento Social", in Helenilda Cavalcanti; Joanildo Burity. Polifonia da Miséria: uma Construção de Novos Olhares. Recife, Fundação Joaquim Nabuco/Massangana, 2002a, pp. 57-70.

"A Sociologia de Pierre Bourdieu (ou como um Autor se Torna Indispensável ao nosso Regime de Leituras)", in Educação e Sociedade (no 78), Campinas, Cedes, 2002b, pp. 57-75. "A Cultura não É um Privilégio Cultural", in Pierre Bourdieu, Alain Darbel (colab. Dominique Schnapper).

0 Amor pela Arte: os Museus de Arte na Europa e seu Público. São Paulo, Edusp/Zouk, 2003a, pp. 7-1 1. . "Educação, Violência Simbólica, Capitais (Cultural e Social) e Destino", in Armando Boito Jr.; Caio Navarro de Toledo (orgs.). Marxismo e Ciências Humanas. São Paulo, Xamã, 2003b, pp. 297-310. . "Universidade na América Latina Hoje: Espaço de Pensamento Crítico ou de Cumplicidades Resignadas?", in Osvaldo Coggiola (org.). América Latina - Encruzilhadas da História Contemporânea. São Paulo, Xamã, 2003c, pp. 253-9.

CATANI, Afrânio Mendes; GUTIERREZ, Gustavo Luis. "Politização e Transparência na Gestão das Universidades Públicas do Estado de São Paulo (Brasil)", in A. M. Catani (org.). Novas Perspectivas nas Políticas de Educação Superior na América Latina no Limiar do Século XXI. Campinas, Autores Associados, 1998, pp. 117-36.

CATANI, A. M.; OLIVEIRA, João Ferreira de. "As Políticas de Educação Superior no Plano Nacional de Educação (PNE)", in Pro-posições. v. 14, no 1 (40),Campinas, pp. 143-8, jan.-abr./2001. 
. Educação Superior no Brasil. Reestruturação e Metamorfose das Universidades Públicas. Petrópolis, Vozes, 2002a.

"Les Politiques d'Enseignement Supérieur au Brésil: Orientation, Principes et Actions", in Maria

Vasconcellos; Dominique Vidal (orgs.). L'Enseignement Supérieur au Brésil. Enjeux et Débats. Paris, Iheal/ Cofecub, 2002b, pp. 101-13.

. "Acesso e Permanência no Ensino Superior: Capacidades, Competição e Exclusão Social", in Antônio Joaquim Severino; Ivani Catarina Arantes Fazenda (orgs.). Políticos Educacionais: o Ensino Nacional em Questão. Campinas, Papirus, 2003, pp. 113-26.

CATANI, M. A.; DOURAD0, Luiz Fernandes. "La Política de Evaluación de la Educación Superior Brasileña en Cuestión", in Revista del Instituto de Investigaciones en Ciencias de la Educación (n-20). Buenos Aires, Miño y Dávila Editores/IICE, 2002, pp. 57-64.

CHAUI, Marilena. "A Universidade em Ruínas", in Hélgio Trindade (org.). A Universidade em Ruínas na República dos Professores. Petrópolis/Rio Grande do Sul, Vozes/Cipedes, 1998, pp. 211-22.

DIAS SOBRINHO, José. Avaliação Institucional da Educação Superior. Petrópolis, Vozes, 2000. . Avaliação: Políticas Educacionais e Reformas da Educação Superior. São Paulo, Cortez, 2003. Universidade e Avaliação. Entre a Ética e o Mercado. Florianópolis, Insular, 2003.

DIXON, Keith. Les Évangelistes du Marché: les Intellectuaels Britanniques et le Néo-libéralisme. Paris, Raisons d'Agir Éditions, 1998.

DOURAD0, Luiz Fernandes. "Reforma do Estado e as Políticas para a Educação Superior nos Anos 90", in Educação e Sociedade (no 80). Campinas, Cedes, 2002.

DOURADO, Luiz Fernandes; CATANI, A. M.; OLIVEIRA, J. F. de (orgs.). Impasses e Perspectivas das Políticas para a Educação Superior no Brasil. Poços de Caldas, Trabalho apresentado à 26@ Reunião Anual da ANPEd, 2003c, mimeo.

Políticas e Gestão da Educação Superior: Transformações Recentes e Debates Atuais. São Paulo/ Goiânia, Xamã/Alternativa, 2003.

"Transformações Recentes e Debates atuais no Campo da Educação Superior no Brasil", in L. F. Dourado; A. M. Catani; J. F. de Oliveira (orgs.). Políticas e Gestão da Educação Superior Transformações Recentes e Debates Atuais. São Paulo/Goiânia, Xamã/Alternativa, 2003, pp. 17-30.

FÓRUM das Seis Entidades. 0 que Precisamos Saber sobre Orçamento. São Paulo, jun./1994, mimeo.

LÉVI-STRAUSS, Claude. Tristes Trópicos. Trad.: Rosa Freire D’Aguiar. São Paulo, Companhia da Letras, [1955] 1996. MAUSS, Marcel. Oeuvres (Tomo III). Paris, Éditions de Minuit, 1969.

MICELI, Sergio (org.). História das Ciências Sociais no Brasil (Vol. 1). São Paulo, Vértice - Editora Revista dos Tribunais/Idesp, 1989.

"A Condição do Trabalho Intelectual (Comentários)", in A. M. Catani e P. H. Martinez (org.). Sete Ensaios sobre o Collège de France. São Paulo, Cortez, 1999.

MUSSE, Ricardo. "Uma Internacional Intelectual", in Jornal de Resenhas, Folha de S. Paulo, São Paulo, 13/set./ 1997.

OLIVEIRA, J. F. de; MOEHLECKE, Sabrina; CATANI, A. M. A Educação como Direito Social: Perspectivas de Universalização do Acesso ao Ensino Superior Gratuito. São Paulo, 2003, mimeo.

ROSANVAIllON, Pierre. Por uma Historia Conceptual de lo Político. Trad.: Marcos Mayer. Buenos Aires, Fondo de Cultura Econômica, 2003.

SAID, Edward W. Cultura e Política. Trad.: Luiz Bernardo Pericás. São Paulo Boitempo, 2003.

SILVA JR., João dos Reis; SGUISSARDI, Valdemar. Novas Faces da Educação Superior no Brasil - Reforma do Estado e Mudanças na Produção. Bragança Paulista/São Paulo, Edusf/Cortez, 2a ed, 2001.

TRINDADE, Hélgio. Universidade em Ruínas na República dos Professores. Petrópolis/Rio Grande do Sul, Vozes/ Cipedes, 1999.

(org.). “As Metáforas da Crise: da 'Universidade em Ruínas' às 'Universidades na Penumbra' na América Latina', in Pablo Gentile (org.). Universidades na Penumbra: Neoliberalismo e Reestruturação Universitária. São Paulo, Cortez, 2001. 